\title{
Consumer-Behavioural Intention Towards The Consumption Of Functional Food In Malaysia: Their Profiles And Behaviours
}

\author{
Hayatul Safrah Salleh, Universiti Malaysia Terengganu, Malaysia \\ Nor Azila Mohd Noor, Universiti Utara Malaysia, Malaysia \\ Nik Hazimah Nik Mat, Universiti Malaysia Terengganu, Malaysia \\ Yusnita Yusof, Universiti Malaysia Terengganu, Malaysia \\ Wan Norhayati Mohamed, Universiti Malaysia Terengganu, Malaysia
}

\begin{abstract}
Unhealthy eating behaviour has been linked to the risks of many chronic diseases all around the world. Functional foods and its association with health benefits and reducing the risk of diseases open a promising avenue for consumers to pursue a healthier life as well as extending their life expectancy. This provides a great market opportunity for functional foods to be developed. Consequently, it has generated considerable consumer interest in functional food consumption. This study describes the profiles and behaviours of the consumers who are willing to consume functional foods in Malaysia. By using mall intercept surveys, data were collected from consumers shopping at hypermarkets in Malaysia. From the analysis undertaken, it was found that the level of consumer-behavioural intention to consume functional food is encouraging. The results indicated that behavioural intention towards functional food tends to be different across gender, age and marital status. However this study found that the extent of consumer-behavioural intention does not vary by ethnicity, religion, income and education. Future study was also proposed.
\end{abstract}

Keywords: Functional Food; Consumer-Behavioural Intention; Malaysia

\section{INTRODUCTION}

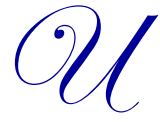
nhealthy diet and bad eating habits are known as major contributors to the global burden of NonCommunicable Diseases (NCD), which is often referred to as chronic diseases. Incidences of NCD, including diabetes, heart disease, high blood pressure, stroke, chronic lung diseases, and certain types of cancer, are growing, affecting people all around the world and in all age groups (WHO, 2011). WHO (2006) reported that $60 \%$ of world annual deaths are due to NCD and approximately $25 \%$ of these deaths were premature and could have been prevented. In the Tenth Malaysia Plan of 2011-2015, the Malaysian government acknowledges that unhealthy eating habits, unhealthy lifestyles and lack of physical activity contribute to the increasing burden of NCD each year (Tenth Malaysia Plan, 2010). Accordingly, this has a significant effect on increasing the cost for medical care due to increasing demand for relatively expensive treatment and long-term rehabilitative care, as well as the loss of economic productivity resulting from excessive mortality and disability. Consequently, it has raised Malaysian consumers' awareness of the link between healthy food and good health. Therefore, consumers have changed the emphasis on satisfying hunger to an emphasis on the promising use of foods to help reduce the risk of disease and to promote well being (Niva, 2007).

Following the trends, food industries have introduced a new category of food product with novel ingredients, and this category has been named "functional food". A food can be said to be functional if it contains a food component that affects one or a limited number of specific function(s) in the body in a targeted way so that it has positive effects on human health. Urala and Lahteenmaki (2007) defined functional food as "Food and drinks 
that provide health benefits that reduces the risk of diseases in addition to its nutritional value". Many studies discovered that functional foods have been proven scientifically to improve overall health, prevent health-related diseases, reduce health problems and reduces obesity rate (Wolk et al., 1999; Pereira et al., 2004). Consequently, this has resulted in considerable public awareness and interest in functional foods in Malaysia. As a result, some consumers are switching to products they perceive to be healthier or more purposeful in their diet. Despite gaining acceptance among consumers, a complete understanding of the consumers' profile and their behaviour towards functional food in Malaysia is presently lacking (Rezai, 2012). In addition, functional food and its association with health benefits is rather a new concept in Malaysia, and it is worth investigating Malaysian behaviour in regards to those foods.

To date, empirical studies on profiling consumer-behaviour intention towards functional food particularly in the Malaysian context is scarce. Most of the previous studies have been conducted in developed countries such as the United States (for example; Gilbert, 1997, 2000; Childs, 1997) and in European countries (for example; Poulsen, 1999; Niva, 2007; Verbeke, 2005; Urala \& Lahteenmaki, 2003, 2004, 2007). However, findings of these studies in many cases produced very mixed results and were not consistent to each other (Verbeke, 2005). To the best of our knowledge, a very limited study in Malaysia has reported empirical research from consumer behaviour perspectives, including on the consumers' profiles and behaviour towards functional food. Thus, the purpose of the present study is to examine consumers' profile towards consumption of functional food in the context of a non-western country, i.e. Malaysia.

\section{LITERATURE REVIEW}

Previous literatures show that intentions have demonstrated a significant positive relationship between intention and behaviour and accurately predicted a variety of action tendencies. In the food context, intention to consume certain type of foods is considered to be one of the most important behavioural indicators. Armitage and Conner (2001) in their meta-analytic review of 185 studies found that intention was a superior predictor of future behaviour. Sparke and Menrad (2006) noted that the stimuli behind purchase intention relating to functional foods are likely to include socio-demographic background and attitudes towards functional foods. These stimuli were considered and processed by the consumer, and as a reaction, the preferences were revealed through purchase decisions or food consumption. Nonetheless, meta-analyses have shown that intentions account for between 20\% and 30\% of the variance in health related behaviours (Armitage \& Conner, 2001; Conner \& Sparks, 2005).

Intention was described as one of "the motivational factors that influence a behaviour and to indicate how hard people are willing to try or how much effort they would exert to perform the behaviour" (Ajzen, 1991; Armitage \& Conner, 2001). Out of the other factors that influence the level of behavioural intention to consume functional food, demographic factors have been said to affect food choice (for example; de Jong et al., 2003; Childs, 1997; Verbeke, 2005; Poulsen, 1999). According to de Jong, et al. (2003), the variable that most affected the consumption of functional foods was the type of functional food, followed by gender, age and education. Childs (1997) identified the U.S. functional food consumer as being female, well educated of a higher income class, and in a broad 35 to 55 age group. Verbeke (2005) indicates that age, gender, education, presence of young children, and presence of sick family members emerge as socio-demographic determinants of functional food acceptance. Whereas, Poulsen (1999) found in his Danish study that women, the elderly and those with lower education were most willing to buy functional foods.

Previous studies showed that women were most likely to be functional food users than men (Bech-Larsen \& Grunert, 2003; Poulsen, 1999; Urala, 2005; Childs \& Poryzees, 1998). In terms of age, middle-aged and elderly consumers were more likely to consume healthy products (Poulsen, 1999; Bech-Larsen \& Scholderer, 2007) and tended to choose foods primarily to prevent disease. Urala (2005) also supports that elderly consumers put more emphasis on the results of food consumption relevant to the prevention of a disease compared to younger consumers. Poulsen (1999) mentions that relatively older respondents within the age group of 55 years and above are more positive about functional foods, compared to other respondents, although no differences were observed with respect to income or educational level. On the contrary, results by Childs and Poryzees (1998), implied that the elderly show less intention to buy a food that prevents a disease compared to younger consumers. 
In general, less educated and lower income groups appear to consume a less healthy diet (Smith \& Baghurst, 1992). Moreover, functional food users are often more educated (de Jong et al., 2004). In contrast, Poulsen (1999) found that education level has no correlation with functional food consumption. Urala (2005) stated that consumer demographic characteristics are only partially correlated with the acceptance of functional foods. Gender, age, income and education are important factors that affect the consumption of functional foods, but the differences between different kinds of these foods are prominent (de Jong et al., 2004). The above contradictory findings suggest that there should not be a generalisation in the demographic profile of functional food consumers. Therefore further study is permitted.

\section{METHODS}

This study is correlational in nature where data was gathered once, to answer the study's research questions. The study was conducted with the intention to obtain a good grasp of the consumer-behavioural intention towards functional food. A survey method was employed because this study strongly believes that survey research is best adopted to obtain personal and social facts, beliefs, and attitudes (Kerlinger, 1973). The unit of analysis for this study was the individual consumer aged 18 and above who went shopping at various hypermarkets in Malaysia. Questionnaires were distributed to the respondents personally.

The sampling procedure used for the present study was mall intercept survey whereby respondents are intercepted during shopping in malls. The demographics information captured in this study were gender, age, marital status, ethnic, religious, monthly household income and level of education. For data collection purposes, 800 questionnaires were distributed to individual consumers in 12 hypermarkets in Malaysia. Out of this number, 486 were returned and 34 questionnaires were excluded because they were incomplete. A total of 452 responses were usable and used for subsequent analysis, giving a response rate of 56.5\%. The sample size appears to be adequate and was comparable to several studies using adult consumers as the study sample in Malaysia. Respective sample sizes for such studies were 439 (Teng et al., 2012) and 200 (Zuraini et al., 2010). In this study the analysis on consumer-behaviour intention to consume functional foods was done using a general functional food without any specification on different categories since functional food is a new concept in Malaysia.

\section{ANALYSIS AND RESULTS}

From the analysis undertaken, it was found that the majority of the respondents were females $(70.4 \%)$ and $29.6 \%$ were males. In total, $37.4 \%$ of the respondents were $18-30$ years old, $37.2 \%$ were $31-40,22.3 \%$ were $41-50$ and only $3.1 \%$ were 51 and above. In terms of religion, the majority of the respondents are Muslim (77.0\%). This is consistent with the percentage of ethnic groups, where $75.7 \%$ of the respondents were Malays, $18.1 \%$ Chinese, $5.1 \%$ Indian and $1.1 \%$ were from other ethnic groups. More than half of the respondents are married $(68.4 \%)$. Those who are single constitute $30.5 \%$ and a minimal $1.1 \%$ divorced. In this study, $19.2 \%$ of the respondents have graduated with master/doctorate degree, $42.0 \%$ graduated with bachelor's degree, $18.8 \%$ with certificate/diploma and $19.9 \%$

from Primary/secondary School. In general, the monthly household income of the respondents is diverse. $23.5 \%$ of the respondents had a household income of below USD1000. Around 38.7\% respondents have household income between USD1001-USD1500. Those with monthly household income between USD1501-USD2500 constitute $16.6 \%$ followed by $11.1 \%$ with household income USD2501-USD3000 and finally $10.2 \%$ respondents have household income of USD3001 and above. Table 1 presents the demographic profile of the respondents. 
Table 1. Profile of the Respondents ( $\mathrm{N}=452)$

\begin{tabular}{|c|c|c|c|}
\hline Variable & Categories & $\mathbf{N}$ & $\%$ \\
\hline \multirow{2}{*}{ Gender } & Male & 134 & 29.4 \\
\hline & Female & 318 & 70.4 \\
\hline \multirow{4}{*}{ Age } & $18-30$ & 169 & 37.4 \\
\hline & $31-40$ & 168 & 37.2 \\
\hline & $41-50$ & 101 & 22.3 \\
\hline & $>50$ & 14 & 3.1 \\
\hline \multirow{5}{*}{ Religion } & Muslim/Islam & 347 & 76.8 \\
\hline & Buddhism/Taoism & 73 & 16.2 \\
\hline & Hindu & 21 & 4.6 \\
\hline & Christianity & 10 & 2.2 \\
\hline & Others & 1 & 0.2 \\
\hline \multirow{4}{*}{ Ethnic } & Malay & 342 & 75.7 \\
\hline & Chinese & 82 & 18.1 \\
\hline & Indian & 23 & 5.1 \\
\hline & Others & 5 & 1.1 \\
\hline \multirow{3}{*}{ Marital Status } & Single & 138 & 30.5 \\
\hline & Married & 309 & 68.4 \\
\hline & Divorced/Widow(er) & 5 & 1.1 \\
\hline \multirow{4}{*}{ Level of education } & Primary/Secondary School & 90 & 19.9 \\
\hline & Certificate/Diploma & 85 & 18.8 \\
\hline & Degree & 190 & 42.0 \\
\hline & Masters/Doctorate & 87 & 19.2 \\
\hline \multirow{5}{*}{ Monthly income } & $<$ USD1000 & 106 & 23.5 \\
\hline & USD1001-USD1500 & 175 & 38.7 \\
\hline & USD1501-USD2500 & 75 & 16.6 \\
\hline & USD2501-USD3000 & 50 & 11.1 \\
\hline & $>$ USD3000 & 46 & 10.2 \\
\hline
\end{tabular}

For the purpose of this study, we listed 10 types of functional foods for the respondents to state their level of familiarity towards those products. In general, the results reveal that the level of respondents' familiarity towards functional food is encouraging. As shown in Table 2, bread (90.3\%) was the highest type of functional food chosen by most respondents, followed by fruit juices, biscuits, milk, eggs, yogurt, cereal, spread and soft drinks. Sweets were the least popular type of functional food chosen by the respondents, with only $48.7 \%$ of respondents stating that they are familiar with that type of food.

Table 2. Respondents' Familiarity towards Functional Food Products

\begin{tabular}{lc}
\hline \multicolumn{1}{c}{ Types } & $\%$ \\
\hline Bread (Fibre-rich with fatty acids/omega 3/wholemeal) & 90.3 \\
Fruit juices (Probiotic/added vitamins or minerals) & 88.3 \\
Biscuits (Added oat/Low cholesterol/low fat/less sugar) & 83.8 \\
Milk (Probiotic/high calcium/Lactose-free/Low fat) & 82.3 \\
Eggs (Omega-3/low cholesterol/added vitamin A \& E) & 80.1 \\
Yogurts (Probiotic yoghurt/low fat) & 76.3 \\
Cereal (Oatmeal with beta-glucan/added vitamins and minerals/low fat) & 76.1 \\
Spread/margarine (Low cholesterol/Low fat content/added vitamin) & 71.0 \\
Soft drinks (Nutritionally fortified drink/energy drink) & 69.7 \\
Sweets (Xylitol/low sugar) & 48.7 \\
\hline
\end{tabular}

Respondents were also asked to give their opinion on what they think of functional food in general. Table 3 shows the frequencies of the elements that come to their mind when they think of functional foods. Overall, the respondents think that functional food are healthy, nutritious, health-enhancing food, is non-toxic in nature, and can prevent certain diseases with the percentage ranging from $84.1 \%$ to $97.8 \%$. Whereas, only $69 \%$ and $72.3 \%$ of the respondents think that functional food was related to probiotic food and contains organic ingredients respectively. 
Table 3. Respondents Opinion on Functional Food in General

\begin{tabular}{lc}
\hline \multicolumn{1}{c}{ Element } & $\%$ \\
\hline Healthy food & 97.8 \\
Natural food product & 76.1 \\
Probiotic food & 69.0 \\
Made from organic ingredients & 72.3 \\
Non-toxic in nature & 86.3 \\
Chemical-free & 76.3 \\
Food that can prevent certain diseases & 84.1 \\
Food supplement & 79.2 \\
Health-enhancing foods & 93.1 \\
Food that contains nutrition & 94.0 \\
\hline
\end{tabular}

With regards to the sources of information regarding functional foods, examination of the responses was shown in Table 4. The higher the percentage, the more likely the respondent used the source. Overall, the respondents were more likely to use electronic media, printed media, word of mouth, professional advice (doctor/nutritionist), social networks and websites to learn about the functional food. It was discovered that electronic media such as television and radio was rated as most likely used of all sources of information by the respondents with $91.8 \%$, followed by $90.7 \%$ via printed media. $78.5 \%$ of the respondents use word of mouth while $64.4 \%$ refer to professional advice from doctor or nutritionist. $62.2 \%$ of the respondents referred to social network and finally $61.9 \%$ obtained information regarding functional food from website.

Table 4. Source of Information Regarding Functional Food

\begin{tabular}{lc}
\hline \multicolumn{1}{c}{ Source } & $\%$ \\
\hline Social network (facebook, twitter, e-mail) & 62.2 \\
Electronic media (TV, radio, billboard) & 91.8 \\
Printed media (magazine, news paper, brochure) & 90.7 \\
Doctor, Nutritionist & 64.4 \\
Word of mouth (family, friends, neighbour) & 78.5 \\
Website & 61.9 \\
\hline
\end{tabular}

It is also interesting to explore if the level of behavioural intention to consume functional food differs across profiles of the respondents. Independent t-test was used to compare the differences in the level of consumerbehavioural intention in terms of gender. A summary of the differences is tabulated in Table 5. The result reveals that there was a significant difference in terms of consumer-behavioural intention between males and females. It was found that females tend to have higher consumer-behavioural intention than males.

Table 5. Consumer-behavioural Intention by Gender $(\mathrm{N}=452)$

\begin{tabular}{lcccc}
\hline Independent Variable & Mean & SD & F- value & p-value \\
\hline Female & 4.38 & .52 & -2.05 & $.04^{*}$ \\
Male & 4.27 & .50 & & \\
\hline
\end{tabular}

Note: ${ }^{*} \mathrm{p}<.05$

The differences in the level of consumer-behavioural intention among respondents were also explored in terms of age, marital status, ethnicity, religion, level of education, and monthly household income. Analysis of variance (ANOVA) was used to test the differences between these variables. Table 6 summarizes the results of the test. It was found that level of consumer-behavioural intention to consume functional foods among respondents did not vary by ethnicity $(\mathrm{F}=.10 ; \mathrm{p}=.96)$, religion $(\mathrm{F}=1.41 ; \mathrm{p}=.23)$, level of education $(\mathrm{F}=.40 ; \mathrm{p}=.76)$ and monthly income $(\mathrm{F}=1.70 ; \mathrm{p}=.15)$. However, the level of consumer-behavioural intention to consume functional foods was found to be different by age $(\mathrm{F}=5.40 ; \mathrm{p}=.001)$ and marital status $(\mathrm{F}=3.40 ; \mathrm{p}=.03)$. Older people tend to have higher intention to consume functional foods compared to younger people and married people have higher intention compared to single persons. 
Table 6. Consumer-behavioural Intention by Age, Marital Status, Ethnicity, Religion, Level of education, and Monthly Income (N=452)

\begin{tabular}{lcc}
\hline & Independent Variable & F-value (p value) \\
\hline Age & $5.40(.001)^{*}$ \\
Marital Status & $3.39(.034)^{*}$ \\
Ethnicity & $.098(.961)$ \\
Religion & $1.41(.231)$ \\
Level of education & $.397(.756)$ \\
Monthly Income & $1.70(.150)$ \\
\hline
\end{tabular}

Note: ${ }^{*} \mathrm{p}<.05$

\section{DISCUSSION}

This study demonstrated that the level of consumer-behavioural intention towards functional food consumption among Malaysian consumers is encouraging. These results is similar to Rezai et al. (2012) and Teng et al. (2012) who found that the majority of the consumers in Malaysia have a positive perception towards the intention to consume functional foods and are willing to pay for such food. Consequently, this leads to the higher percentage of the consumers who are familiar with functional food products listed in the study. This is comparable to Landstrom et al. (2007), whose findings revealed that $84 \%$ of Swedish consumers were familiar with the concept of functional foods and the majority of them had consumed or purchased such products. One plausible reason to explain this finding is due to the positive belief of the consumers towards functional foods - that is, functional foods are a healthy, nutritious, health-enhancing food, is non-toxic in nature and can prevent certain diseases - which motivates a higher interest in consuming such foods. This is in line with Rezai (2012) and Verbeke (2005) who found that consumer belief in the health benefits of functional foods is the main positive determinant of acceptance towards such food.

The findings regarding demographic variables have been somewhat indefinite. Some studies found nonsignificant relationships between the different demographic variables and consumer-behavioural intention while others have found the relationship to be significant. In this study, the level of consumer-behavioural intention does significantly vary by gender. Females were found to have higher consumer-behavioural intention to consume functional food compared to males. One explanation for this was because females were assumed to be responsible for household purchase, childcare and day-to-day family matters (Bech-Larsen \& Scholderer, 2007; Lee, 2008). The maternal role of females may shape them to become more concerned about health and family safety. Therefore they are more sensitive and more willing to change their current lifestyle to be healthier. Another plausible reason is that, in general, females have been shown to be more reflective about food and health issues and they are seen to have more moral and ecological misgivings about eating certain foods than men (Gilbert, 1997; Verbeke \& Vackier, 2005). The result is consistent with Teng et al. (2012), Verbeke (2005) and Landstrom et al. (2007) who significantly demonstrated that female respondents were largely more willing to pay and consume functional food compared to males.

Older consumers were also found to have higher level of intention to consume functional food compared to younger consumers. One reason for this finding may be due to the older respondents' own experience with illness that may increase probability of functional food acceptance among them. Other than that, elderly consumers were more conscious about health because they have higher probability of being diagnosed with some disease than those who were younger. Therefore, older people were more attentive towards food choice due to the potential association with higher food risk aversion. Verbeke (2005) claimed that this relation is explained by the older consumers' own experience with health problems. This is in contrast with Rezai et al. (2012) and de Jong et al. (2003) who reported that younger consumers were more aware and interested in functional food than older people.

Likewise, marital status was found significantly different in relation to the level of consumer-behavioural intention perform by the consumers. Consumers who were married were found to perform higher consumerbehavioural intention to consume functional food than single consumers. This is consistent with findings by Poulsen (1999) and Verbeke (2005) in their study in Europe. It may be suggested that married people were more inclined to think of how unhealthy food can bring negative impact towards health, not only to themselves but also to their family. This could be a string motivation for married people to consume functional foods. 
The present study also found that the extent of consumer-behavioural intention does not vary by ethnicity and religion. This is plausibly due to the fact that the majority of Malaysians are Muslim Malays. Our sample population consists of about $75.7 \%$ Malay and $76.8 \%$ Muslim. This overwhelming majority can lead to statistical invariance that can explain why intention to consume functional food does not differ by ethnicity. Another plausible reason may due to the rapid economic development is changing Malaysia's social structure especially in terms of social interaction, lifestyle and shared values. These changes increase the extent to which Malaysian are exposed to each other cultures and value systems. Social interaction among members of different ethnic groups and religions promote mutual understanding, respect and acceptance of functional food among cultures (Hassan, 2011).

Similarly, in this study, it was found that level of education and income were not significantly related to the level of consumer-behavioural intention. This result is similar to Poulsen (1999) who mentions that no differences were observed with respect to income and educational level in his study. This result is also supported by Urala and Lahteenmaki (2007) who stated that both higher and lower education positively correlate with willingness to use functional food in Finland. One plausible reason to explain this finding is that the consumers' strong belief towards functional foods is related to the positive health effects of the products and health consciousness among consumers. Another plausible reason may relate to the fact that functional foods can prevent certain chronic diseases such as cancer and heart disease, resulting in significant implications on huge healthcare costs and relatively expensive treatment and long-term rehabilitative care to cure. Therefore, consumers are willing to spend money to buy functional foods for the promise of a healthier life rather than spending on drugs and medication. This is in contrast with Hilliam (1996) who noted that consumers in Europe with higher socio-economic group (high income and education) are willing to purchase functional food due to ability to pay and better knowledge compared to low income consumers.

\section{CONCLUSION}

This study aimed at investigating the consumer-behavioural intention to consume functional food in the context of Malaysia. The analysis undertaken indicated that the level of consumer-behavioural intention to consume functional food among Malaysian consumers is encouraging. Respondents from different ethnic, religion, level of education and income groups were found to perform similar levels of intention to consume functional foods. However, females were found to exhibit higher levels of consumer-behavioural intention compared to males. Similarly, older and married people were found to demonstrate higher levels of behavioural intention to consume functional food.

On a final note, this research was based on the response of adult consumers aged 18 and above and thus the results do not represent the Malaysian population in general. Other segments, such as teenagers and University students, who may have different behavioural intentions towards functional food, should be investigated. Also, additional studies comparing behavioural intention of consumers from different regions of Malaysia might produce interesting findings.

\section{AUTHOR INFORMATION}

Dr. Hayatul Safrah Salleh is a Senior Lecturer in the School of Maritime Business and Management, Universiti Malaysia Terengganu. She completed her Bachelor in Management at Universiti Sains Malaysia. She obtained her MBA from University of Wales, Cardiff, UK and a Doctor of Business Administration from Universiti Utara Malaysia. Her research interest is in the area of consumer behaviour, decision-making style, green marketing, shopping orientation and service marketing. She was also the reviewer for a few journals. She has also involved in several research grant projects, has presented papers at international conferences and has published articles in several journals. Email: hayatul@umt.edu.my

Associate Professor Dr. Nor Azila Mohd Noor holds a Bachelor Degree in Business Administration from Universiti Utara Malaysia; a Master of Science Degree in Marketing from University of Stirling, Scotland; and a $\mathrm{PhD}$ in Marketing from Universiti Sains Malaysia. Her research works have been published in many academic journals. She has also presented her research works in many local and international conferences. She was also the 
associate editors/reviewers for a few journals. She has successfully supervised many Masters and PhD students. Dr Nor Azila also involved in several researches, consultancies and training activities. Email: azila@uum.edu.my

Dr. Nik Hazimah Nik Mat is a Senior Lecturer in the School of Maritime Business and Management, Universiti Malaysia Terengganu. She studied at Edith Cowan University, Australia, International Islamic University Malaysia and University of Technology Malaysia. Her recent $\mathrm{PhD}$ research focused on the line managers' involvement in the HRM function. Her area of passion is on the transformation of the HRM function in the modern and complex environment, the role of HRM policies and practices to improve employees' performance and the changing demand of the line managers' HRM role in the organization. She is a member of Australian and New Zealand Academy of Management (ANZAM). Email: nikhazimah@umt.edu.my

Dr. Yusnita Yusof is a lecturer of Tourism Management and Tourism Marketing at Universiti Malaysia Terengganu. She received her Bachelor of Business Administration (Hons.) from Universiti Utara Malaysia. She pursued her Master of Tourism Management from Griffith University, Australia. Upon completion of her master, she worked as Research Officer under domestic tourist project at Universiti Sains Malaysia. She obtained her Ph.D. on Tourism Management from Universiti Malaysia Terengganu. She has been teaching various subjects on tourism, management and marketing. Her research interests include tourism management, tourism marketing, community based tourism and the impacts of tourism. She has published her works in several journals and actively involved in various conferences. Email: yusnitayusof@umt.edu.my

Dr. Wan Norhayati Mohamed is a senior lecturer in a field of Management and Marketing. She obtained her PhD in Management from Universiti Malaysia Terengganu. She has more than 15 years of experience in teaching management and marketing courses. Her main research interest is in the area organizational behavior, human resource management, life satisfaction, and service marketing. She has also involved in several research grant projects, has presented papers at international conferences and has published articles in several journals. Email: wannor@umt.edu.my

\section{REFERENCES}

Ajzen, I. (1991). The theory of planned behaviour. Organisational Behaviour Human Decision Process. 50, 179211.

Armitage, C. J. \& Conner, M. (2001). Efficacy of the theory of planned behaviour: a meta-analytic review. The British Journal of Social Psychology, 40(4), 471-499.

Bech-Larsen, T. \& Grunert, K. G. (2003). The perceived healthiness of functional foods: a conjoint study of Danish, Finnish and American consumers' perception of functional foods. Appetite, 49, 9-14.

Bech-Larsen, T. \& Scholderer, J. (2007). Functional foods in Europe: Consumer research, market experiences and regulatory aspects. Trends in Food Science \& Technology, 18, 231-234.

Childs, N. M. (1997). Foods that help prevent disease: Consumer attitudes and public policy implications. Journal of Consumer Marketing, 14(6), 433-447.

Childs, N. M., \& Poryzees, G. H. (1998). Foods that help prevent disease: consumer attitudes and public policy implications. British Food Journal, 9, 419-426.

Conner, M., \& Sparks, P. (2005). Theory of Planned Behaviour and Health Behaviour. In M. Conner, \& P. Sparks (Eds.), Predicting health behaviour: Research and practice with social cognition models, 2nd edition (pp. 170-222). Mainhead: Open University Press.

de Jong, N., Ocke', M. C., Branderhorst, H. A. C., \& Friele, R. (2003). Demographic and lifestyle characteristics of functional food consumers and dietary supplement users. British Journal of Nutrition, 89, 273-281.

Gilbert, L. (1997). The consumer market for functional foods. Journal of Nutraceuticals, Functional and Medical Foods, 1(3), 5- 21.

Gilbert, L. (2000). The functional food trend: what's next and what Americans think about eggs. Journal of the American College of Nutrition, 19(5), 507-512.

Hassan, S. H. (2011). Managing conflicting values in functional food consumption: the Malaysian experience. British Food Journal, 113(8), 1045-1059.

Hilliam, M. (1996). Functional Foods: The Western consumer viewpoint. Nutrition Reviews, 11, 189-194

Kerlinger, F. N. (1973). Foundations of behavioural research. New York: Holt, Rinehart, \& Winston 
Landstrom, E., Hursti, U. K., Becker, W., \& Magnusson, M. (2007). Use of functional foods among Swedish consumers is related to health-consciousness and perceived effect. The British journal of nutrition, 98(5), 1058-1069

Lee, K. (2008). Opportunities for green marketing: young consumers. Marketing Intelligence \& Planning, 26(6), 573-586.

Niva, M. (2007). All foods affect health: Understandings of functional foods and healthy eating among healthoriented Finns. Appetite, 48, 384-393.

Pereira, M. A., O'reilly, E., Augustsson, K., Fraser, G. E., Goldbourt, U., Heitmann, B. L., et al. (2004). Dietary fibre and risk of coronary disease: a pooled analysis of cohort studies. Archives of International Medicine, $164,370-376$.

Poulsen, J. B. (1999). Danish consumers' attitudes towards functional foods. MAPP Working Paper No. 62, The Aarhus School of Business, Aarhus University, Aarhus, Denmark.

Rezai, G., Teng, P.K., Mohamed, Z., \& Shamsudin, M.N (2012). Functional Food Knowledge and Perceptions among Young Consumers in Malaysia. International Journal of Economics and Management Sciences, 6 , 28-33.

Smith, A., \& Baghurst, K. (1992). Public health implications of dietary differences between social status and occupational category groups. Journal of Epidemiology and Community Health, 46, 409-416.

Sparke, K., \& Menrad, K., (2006). Cross-European and functional food related consumer segmentation for new product development. Paper prepared for presentation at the 98th EAAE seminar 'Marketing dynamics within the global trading system: New perspectives'. Chania, Crete, Greece, 29 June-2 July 2006

Teng, P.K., Rezai, G., Mohamed, Z. \& Shamsudin, M. N. (2012). Malaysian Consumers' Willingness-to-pay for Functional Food. In Proceedings of $2^{\text {nd }}$ International Conference on (ICM 2012), Kedah, Malaysia, June $11-12,2012$.

Tenth Malaysia Plan 2011-2015 (2010). Published by The Economic Planning Unit Prime Minister's Department, Putrajaya.

Urala, N. (2005). Functional foods in Finland: Consumers' views, attitudes and willingness to use. Espoo 2005, VTT Publications 581, Finland.

Urala, N., \& Lahteenmaki, L. (2003). Reasons behind consumers' functional food choices. Nutrition \& Food Science, 33(4), 148-158.

Urala, N., \& Lahteenmaki, L. (2004). Attitudes behind consumers' willingness to use functional foods. Food Quality \& Preference, 15, 793-803.

Urala, N., \& Lahteenmaki, L. (2007). Consumers' changing attitudes towards functional foods. Food Quality and Preference, 18, 1-12.

Verbeke, W. (2005). Consumer acceptance of functional foods: socio-demographic, cognitive \& attitudinal determinants. Food Quality \& Preference, 16(1), 45-57.

Verbeke, W., \& Vackier, I. (2005). Individual determinants of fish consumption: application of the theory of planned behaviour. Appetite, 44(1), 67-82.

WHO (2011). World Health Statistic 2011. Retrieved April 25, 2012 from http://www.who.int/whosis/whostat/2011/en/index.html

WHO (2006). WHO: Preventing chronic disease: a vital investment: WHO global report, 2005, Obesity \& Overweight, Fact Sheet No. 311.

Wolk, A., Manson, J. E., Stampfer, M. J., Colditz, G. A., Hu, F. B., Speizer, F. E., et al. (1999). Long-term intake of dietary fibre and decreased risk of coronary heart disease among women. Journal of the American Medical Association, 281, 1998-2004.

Zuraini, M.I., Haslina, H. \& Nur Hasniza, I (2010). Identifying the Customers'Acceptance Levels towards Healthy Cakes at Hypermarkets in Klang Valley, Malaysia. Asian Social Science, 6(8), 170-177. 


\section{NOTES}

